\title{
Translation of "abnormal behavior" referral in emergency department, what does it mean for the C\&L psychiatrist?
}

\begin{abstract}
The presentation of any psychiatric patient to a general hospital Emergency Department is at best a potential for disruption of the routine and requiring special care, special attention and precautions and definitely needing special logistics. The Emergency physician intervention is an emergency measure: IE life or limb saving intervention, so medical stabilization is a major goal. When it comes to well and seemingly healthy presentation with psychiatric symptoms or behavioral disturbances, the referral is made directly to the psychiatrist with little history of the current presentation and usually it is filed to consultation as "Abnormal Behavior". We looked into this group to see what is hidden behind the blanket that label. Our results were congruent with many other published papers as to the frequency of nonpsychiatric cases referred to psychiatry. A practical recommendation was derived from the experience in this paper we are discussing the results and the recommendations.
\end{abstract}

Volume 6 Issue 4 - 2016

\author{
Adel S Zaraa, ${ }^{1,2}$ Maria A Ribot Miquel, ${ }^{3}$ Nahid \\ M Elhassan ${ }^{3}$ \\ 'Professor of Clinical Psychiatry, OUCOM, Ohio, USA \\ ${ }^{2}$ Emergency Department, HMC, Doha, Qatar \\ ${ }^{3}$ Clinical Fellow of Consult Liaison Psychiatry, Weill Cornell \\ Medical College, Qatar
}

Correspondence: Adel S Zaraa, Professor of Clinical Psychiatry, OUCOM, Ohio, USA, Po. Box 3050, HMC, Department of Emergency, Doha, Qatar, Tel 974 33427277, Email drzaraa@gmail.com

Received: August 0I, 2016 | Published: August 04, 2016

Keywords: consult liaison psychiatry, delirium, abnormal behavior, emergency psychiatry

\section{Introduction}

The Emergency department in a general hospital is the first entry point for psychiatric and non- psychiatric patients. The Rate of referral to Consultation Liaison team is high and with different reasons. This study focused only on referred cases labeled as "'abnormal behavior" by the emergency room physician; there were (201)patients in the period of four months who were referred with the chief complain documented as "Abnormal Behavior"; we proceeded to review those cases through a prospective cross -sectional descriptive study.

\section{Method and results}

Data was collected and analyzed and the findings were as follows; $22.4 \%$ of referred cases labeled as abnormal behavior were not psychiatric cases per se but met the criteria for the diagnosis of Delirium, this result is in congruence with the findings cited in Emergency rooms across the USA were one of five or $20 \%$ of all psychiatric patients met the criteria for delirium. Most of the patients were male between 21-40 years old (73\%) that also is a realistic reflection of the demographic representation of the population in Qatar and it is similar to other study. ${ }^{1}$ In this subgroup the Majority of patients were Arab 21\%, Indian 16\% and Bengali 16\%. Among those who were diagnosed with psychiatric illnesses $62 \%$ were admitted and $38 \%$ got discharged (Figure 1-3).

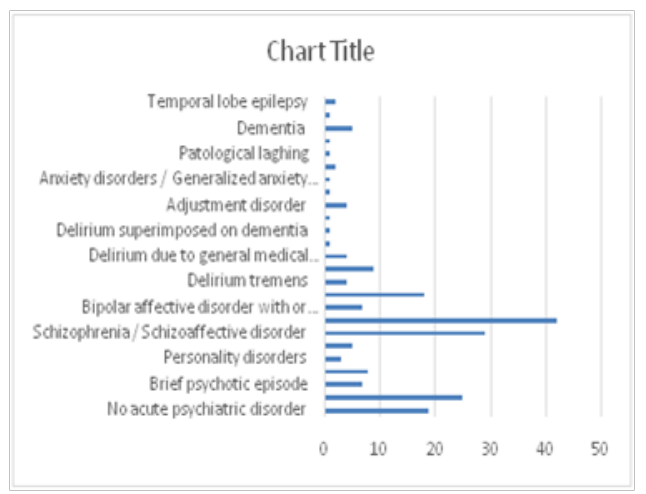

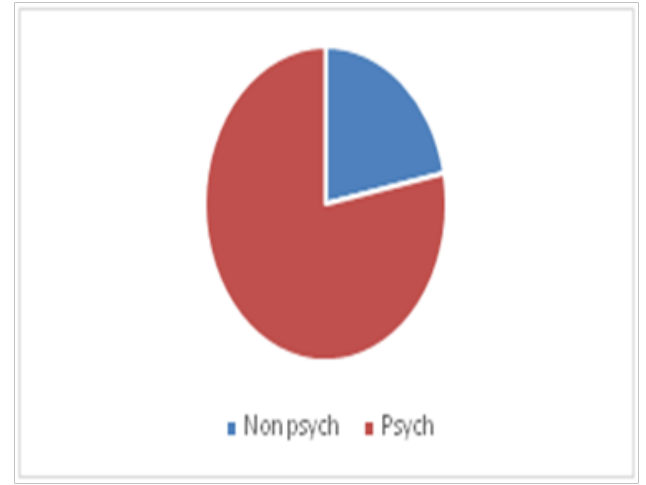

Figure I Flow chart.

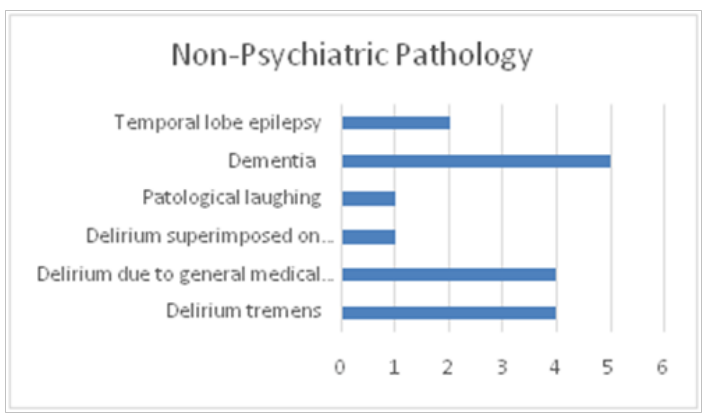

Figure 2 Non-Psychiatric Pathology.

\section{Discussion}

An initial observation was that the presence of Emergency Room Psychiatric service has encouraged the ED doctors to increase the Rate of referral to psychiatry but on the other hand the referrals labeled "abnormal behavior "found to be high compared to other studies. Increase rates of psychiatric disorders among this population are replicated in this study. $20 \%$ of the patients who were psychiatric patients 
were discharged. And fifth of the referral were not psychiatric cases. Such confusion of psychiatric cases is not unique to this study. ${ }^{2,3}$

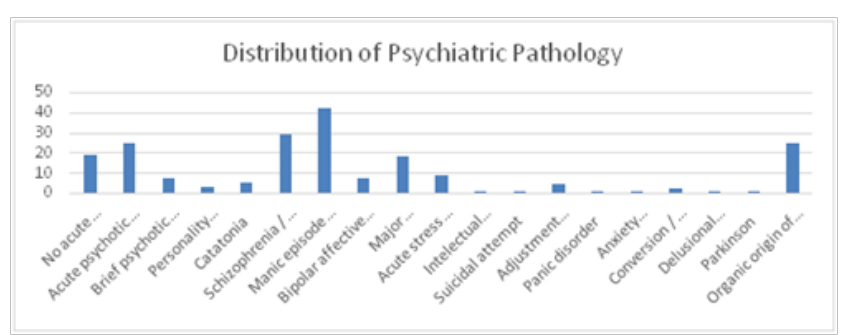

Figure 3 Distribution of Psychiatric Pathology.

\section{Conclusion and recommendations}

Translation of abnormal behavior in emergency unit sheds some light on the attitude and perception of psychiatry among medical doctors and community at large. So Improvement of Training of emergency doctors in psychiatry is highly needed. The Emergency Department at this hospital has incorporated the residents' psychiatric rotation as part of the core curriculum; also the different ER fellowship programs were instrumental in holding series of psychiatric lectures and workshops in their educational activities. These steps would definitely change the referral justification in the near future. A follow up study is warranted to measure the impact of education and awareness.

\section{Acknowledgments}

None.

\section{Conflicts of interest}

Author declares there are no conflicts of interest.

\section{Funding}

None.

\section{References}

1. Pavan Kumar K, Sinjoni Roy, Ravinder Anaveni. A Descriptive Study of Referral Pattern in Department of Psychiatry in a Tertiary Care Hospital. Telangana Journal of Psychiatry. 2015;1(1):43-48.

2. Makhal Manabendra, Majumder Uttam. Psychiatric Comorbidity among referred in-patients and the need for consultation, Delhi Psychiatric $J$. 2013;16(1):122.

3. Kelkar DK, Chaturvedi SK, Malhotra MDS. A Study Of Mergency Psychiatric Referrals in a Teaching General Hospital. Indian $J$ Psychiatry. 1982;24(4):366-369. 